\title{
Serotypes, Antibiogram and Genetic Relatedness of Pseudomonas aeruginosa Isolates from Urinary Tract Infections at Urology and Nephrology Center, Mansoura, Egypt
}

\author{
Shaymaa H. Abdel-Rhman1,2, Dina E. Rizk ${ }^{2 *}$ \\ ${ }^{1}$ Department of Pharmaceutics and Pharmaceutical Biotechnology, Faculty of Pharmacy, Taibah University, AlMadinah Al \\ Munawwarah, KSA \\ ${ }^{2}$ Department of Microbiology and Immunology, Faculty of Pharmacy, Mansoura University, Mansoura, Egypt \\ Email: *dena@mans.edu.eg, *dinaeid2013@yahoo.com
}

How to cite this paper: Abdel-Rhman, S.H. and Rizk, D.E. (2018) Serotypes, Antibiogram and Genetic Relatedness of Pseudomonas aeruginosa Isolates from Urinary Tract Infections at Urology and Nephrology Center, Mansoura, Egypt. Advances in Microbiology, 8, 625-638.

https://doi.org/10.4236/aim.2018.88042

Received: June 20, 2018

Accepted: August 27, 2018

Published: August 30, 2018

Copyright (c) 2018 by authors and Scientific Research Publishing Inc. This work is licensed under the Creative Commons Attribution International License (CC BY 4.0).

http://creativecommons.org/licenses/by/4.0/

\section{cc) (i) Open Access}

\begin{abstract}
Background: Pseudomonas aeruginosa ( $P$. aeruginosa) is an opportunistic pathogen that represents a major problem in many hospitals because of its increased resistance to antibiotics and the ability to cause nosocomial infections. The present study aimed to phenotype and genotype isolates of $P$. aeruginosa from inpatients with UTIs at Urology and Nephrology center, Mansoura, Egypt to study their relatedness. Methods: Thirty nine isolates of $P$. aeruginosa were phenotypically typed by determination of $\mathrm{O}$-serotypes by slide agglutination technique and antimicrobial resistance patterns by disk-diffusion method. The genetic diversity of isolates was illustrated by performing RAPD-PCR using M13 primer. Results: Serotypes O11, O6 and $\mathrm{O} 10$ were the most prevalent. Isolates showed high resistance rates to antipseudmonal antibiotics with high incidence (51.3\%) of multidrug resistance (MDR). Amikacin was the most effective. A significant correlation was found between $\mathrm{O6}, \mathrm{O} 10$ and MDR. A relatively high polymorphism was demonstrated among $P$. aeruginosa isolates by using RAPD-M13 fingerprinting. Cross transmission was suggested by phenotypically and clonally identical isolates. Conclusion: The study demonstrates the role of combining both classical and molecular typing as a valuable mean to study the origin and cross transmission of $P$. aeruginosa in UTIs for better assessment of treatment and infection control.
\end{abstract}

\section{Keywords}

P. aeruginosa, O-Serotype, Antibiogram, RAPD-M13 Fingerprint 


\section{Introduction}

$P$. aeruginosa is a cosmopolitan Gram-negative bacterium that is considered as a major frequent cause of nosocomial infections [1]. It is a leading cause of human opportunistic infections particularly in immunocompromized patients [2] [3] [4]. Urinary tract infections are among the most predominant nosocomial infections. $P$. aeruginosa is responsible for $7 \%-10 \%$ of such infections [5].

For epidemiological purpose, typing techniques are required to recognize nosocomial transmission by establishing clonal relationships between isolates. $P$. aeruginosa is the third most common pathogen associated with hospital-acquired catheter-associated UTIs isolates [6]. Typing of $P$. aeruginosa relied on phenotypic characters such as lipopolysaccharide (LPS) serotypes, susceptibility to antimicrobials, phage susceptibility typing and bacteriocin production [7].

LPS contains $\mathrm{O}$ antigen, a repeating polysaccharide portion that has been used for the classification of $P$. aeruginosa isolates. The International Antigenic Typing Scheme (IATS) reported 20 different serotypes based on the expression of the O-antigen moiety [8] [9].

Infections caused by $P$. aeruginosa are difficult to treat because of the limited susceptibility to antibiotics which is due to its inherent resistance to many drug classes and the ability to develop further resistance mechanisms to available antibiotics [10]. MDR $P$. aeruginosa has increased worldwide in the last century [3]. They are usually isolated from nosocomial infections [11]. It is of a great importance to study the susceptibility of $P$. aeruginosa isolates to commonly used antibiotics. Antibiogram can be used as an epidemiological indicator that may guide the best choice of antimicrobial agents in infections' management [12].

Molecular typing methods have been used to study the genetic diversity of $P$. aeruginosa. DNA typing methods include ribotyping, pulsed field gel electrophoresis (PFGE), repetitive element based PCR (rep-PCR) and random amplification of polymorphic DNA (RAPD) [13] [14]. RAPD-PCR is one of the molecular techniques used for $P$. aeruginosa typing. It is based on the use of single primers of arbitrary nucleotide sequence for amplification of random DNA segments [15]. RAPD-PCR is a simple, low cost genotyping method capable of generating a large number of genetic markers using small amount of DNA without the need for molecular characterization of the genome of the species under investigation [16].

The aim of the present study was to investigate the prevalence of O-serotypes, resistance phenotypes of clinical urine $P$. aeruginosa isolates obtained from Urology and Nephrology center, Mansoura, Egypt. Also, RAPD genotyping was conducted to characterize their genetic diversity. Assessment of obtained data was done to verify any association of serotypes with resistance pattern or RAPD genotypes. 


\section{Materials and Methods}

\subsection{Bacterial Isolates}

A total of non-replicate $39 P$. aeruginosa isolates obtained from patients at Urology and Nephrology center, Mansoura University, Egypt were included in this study. The study was approved by the research ethics committee of faculty of Pharmacy, Mansoura University, Egypt.

\subsection{Identification of $P$. aeruginosa}

$P$. aeruginosa isolates were identified morphologically (gram stain and motility test) [17] and biochemically (oxidase, $\mathrm{H}_{2} \mathrm{~S}$ production, gelatin liquefaction, arginine hydrolysis, pyocyanin pigment production and growth at $42^{\circ} \mathrm{C}$ ) [18].

\subsection{Serotyping}

Serotyping of $P$. aeruginosa was performed by slide agglutination technique using specific 4 polyvalent and 16 monovalent antisera according to recommendation of the manufacturer's protocol (Bio-Rad ${ }^{\oplus}$, France) according to Glupczynski et al. [19]. However, the determinations of $P$. aeruginosa serogroups were based on the International Antigen Typing Scheme (IATS) according to Legakis et al. [9].

\subsection{Antimicrobial Susceptibility Testing}

Antibiotic susceptibility of $P$. aeruginosa isolates was carried out by Kirby-Bauer disk diffusion technique according to Clinical Laboratory Standard Institute guidelines (CLSI 2014) [20]. Levofloxacin (LEV $5 \mu \mathrm{g}$ ), ciprofloxacin (CIP $5 \mu \mathrm{g}$ ), amikacin (AK $30 \mu \mathrm{g})$, gentamicin (CN $10 \mu \mathrm{g}$ ), imipenem (IPM $10 \mu \mathrm{g}$ ), piperacillin (PRL $100 \mu \mathrm{g}$ ) and cefoperazone/sulbactam (CFS 75/30 mg) [21] antibiotic discs ((Oxoid, UK)) were used. Resistance to at least three drugs from different classes was considered MDR [22].

\subsection{RAPD-M13 Genotyping}

Genomic DNA was obtained by modified boiling method of Englen and Kelley [23]. RAPD-PCR analysis was performed with M13 primer

(5'-GAGGGTGGCGGTTCT-3') [24]. The reaction mixture consisted of $4 \mu \mathrm{L}$ genomic DNA, $10 \mu \mathrm{L}$ 5X Green GO Taq Flexi buffer, $1.5 \mu \mathrm{L}$ dNTP Mix $(10 \mathrm{mM}$, PROMEGA, USA), $3 \mu \mathrm{L} \mathrm{MgCl}_{2}$ solution $(25 \mathrm{mM}), 1 \mu \mathrm{L} \mathrm{M} 13$ primer $(10 \mu \mathrm{M})$ and $0.25 \mu \mathrm{L}$ Go Taq G2 Flexi DNA Polymerase (500 U, PROMEGA, USA) in a final volume of $50 \mu \mathrm{L}$. The cycling conditions were carried in thermal cycler (FPROGO2D, Tchne LTD, Oxford Cambridge, UK) as follows: initial denaturation at $94^{\circ} \mathrm{C}$ for $5 \mathrm{~min}, 35 \mathrm{cycles}$ of $94^{\circ} \mathrm{C}$ for $60 \mathrm{~s}$, annealing at $30^{\circ} \mathrm{C}$ for $150 \mathrm{~s}$ and extension at $73^{\circ} \mathrm{C}$ for $150 \mathrm{~s}$. The resulting PCR products were electrophoresed using $2 \%$ agarose gel stained by ethdium bromide and visualized in a gel documentation system. 


\subsection{Statistical Analysis}

Data analysis was done by chi square probability test using GraphPad Prism5 software to find association between studied characteristics. $P$ value of $\leq 0.05$ was considered significant.

Combined datasets of serotype, antibiogram, RAPD-PCR profile of M13 were created to construct a dendrogram based on the unweighted pair group method with an arithmetic average (UPGMA) using online software.

\section{Results}

In the current study, 39 clinical isolates of $P$. aeruginosa were isolated from patient with UTIs. They were identified morphologically and by conventional biochemical tests.

\subsection{Serotyping}

$P$. aeruginosa isolates $\mathrm{O}$-serotyping gave 9 different serotypes representing 6 serogroups (B, C, E, G, H and I) (Table 1). The incidence of serotypes among the isolates differs significantly $(P<0.0001)$. The most frequent serotypes were O11, O6 and O10 representing $30.8 \%, 20.5 \%$ and $15.4 \%$ of isolates, respectively. Serogroups B (O2/O5/O16), C (O7/O8) and I (O1) were found in $20.5 \%, 5.1 \%$ and $7.7 \%$ of isolates.

\subsection{Antimicrobial Susceptibility}

The highest percent of resistance among isolates was to piperacillin (61.5\%) followed by resistance to cefoperazone/sulbactam (56.4\%) and gentamicin (53.8\%). Amikacin was the most effective as only $25.6 \%$ of isolates was resistant. Isolates showed the same level of resistance (48.7\%) to both ciprofloxacin and levofloxacin. Imipenem resistance was demonstrated by 14 (35\%) isolates. While 20 (51.3\%) isolates were MDR, only 10 (25.6\%) isolates were sensitive to all tested antibiotics.

Table 1. Distribution of serotypes among $P$. aeruginosa isolates.

\begin{tabular}{cccc}
\hline Serotype & Serogroup & \multicolumn{3}{c}{ Number (\%) } \\
\hline O1 & I & 3 & $(7.7)$ \\
O2 & B & 4 & $(10.2)$ \\
O5 & B & 3 & $(7.7)$ \\
O6 & G & 8 & $(20.5)$ \\
O7 & C & 1 & $(2.5)$ \\
O8 & C & 1 & $(2.5)$ \\
O10 & H & 6 & $(15.4)$ \\
O11 & E & 12 & $(30.8)$ \\
O16 & B & 1 & $(2.5)$
\end{tabular}


Regarding the resistance pattern, 13 patterns were found among the studied isolates. A1 pattern that represents resistance to all tested antibiotics was demonstrated by 7 (17.9\%) isolates (Table 2 ).

\subsection{Relationship between Serotypes and Antibiotic Resistance}

Regarding resistance to each antibiotic, the distribution of serotypes among resistant isolates to levofloxacin, ciprofloxacin and piperacillin differs significantly $(P$ value $=0.0085,0.0085$ and 0.0165 , respectively $)$. There was a high association between resistance to these antibiotics and certain serotypes (O6, O10 and O11). For either Levofloxacin or ciprofloxacin, resistance represented $87.5 \%(7 / 8)$, $66.7 \%(4 / 6)$ and $41.6 \%(5 / 12)$ of O6, O10 and O11 isolates, respectively. Piperacillin resistance represented $87.5 \%(7 / 8), 66.6 \%(4 / 6)$ and $58.3 \%(7 / 12)$ of O6, $\mathrm{O} 10$ and $\mathrm{O} 11$ isolates, respectively (Figure 1).

The incidence of MDR isolates differs significantly among different serotypes $(P=0.0608)$. They were highly associated with serotype O6 (87.5\%), O10 $(66.6 \%)$ and O11 (41.6\%). Also, A1 pattern was significantly associated with serotype $\mathrm{O} 6$ and $\mathrm{O} 10(P=0.0486)$ and A6pattern with serotype $\mathrm{O} 6(\mathrm{P}=0.0348)$.

\subsection{RAPD-M13 Genotyping}

RAPD fingerprinting of $39 \mathrm{P}$. aeruginosa isolates showed 10 different genotypic profiles (P1-P10). Each profile comprised 2 to 8 DNA fragments of different sizes (Figure 2). The incidence of profiles differs significantly $(P=0.0009)$. P1 was

Table 2. Antibiograms showing resistance pattern of $P$. aeruginosa isolates.

\begin{tabular}{ccc}
\hline Antibiograms & Resistance pattern & No. of isolates (\%) \\
\hline A1 & LEV/CIP/AK/CN/IPM/PRL/CFS & $7(17.9)$ \\
A2 & LEV/CIP/CN/IPM/PRL/CFS & $3(7.7)$ \\
A3 & LEV/CIP/AK/CN/PRL/CFS & $2(5.1)$ \\
A4 & LEV/CIP/CN/PRL/CFS & $3(7.7)$ \\
A5 & AK/CN/IPM/PRL/CFS & $1(2.5)$ \\
A6 & LEV/CIP/CN/PRL & $2(5.1)$ \\
A7 & CN/IPM/PRL/CFS & $1(2.5)$ \\
A8 & LEV/CIP/CN/CFS & $1(2.5)$ \\
A9 & PRL/CFS & $4(10.3)$ \\
A10 & LEV/CIP & $1(2.5)$ \\
A11 & IPM & $2(5.1)$ \\
A12 & CN & $1(2.5)$ \\
A13 & PRL & $1(2.5)$ \\
Sensitive & - & $10(25.6)$ \\
\hline
\end{tabular}

LEV: levofloxacin, CIP: ciprofloxacin, AK: amikacin, CN: gentamicin, IPM: imipenem, PRL: piperacillin and CFS: cefoperazone/sulbactam. 

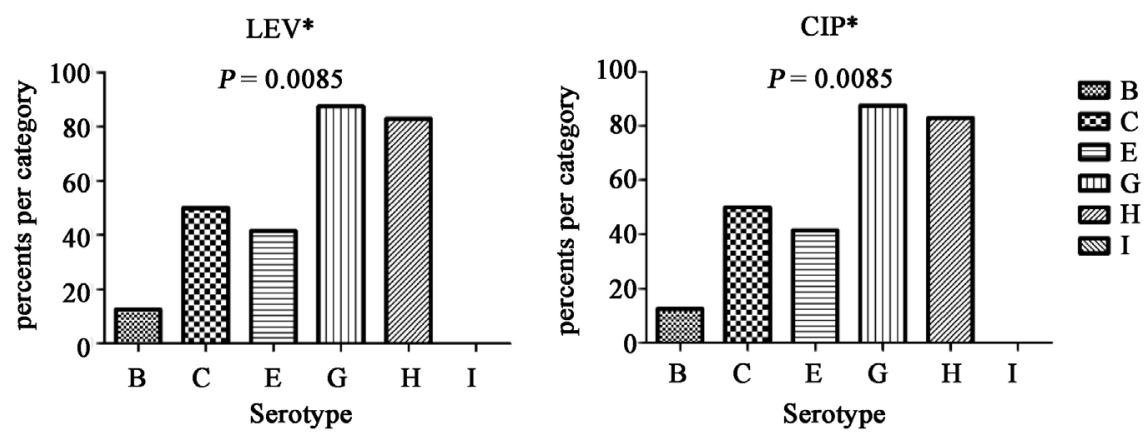

$\mathrm{AK}$
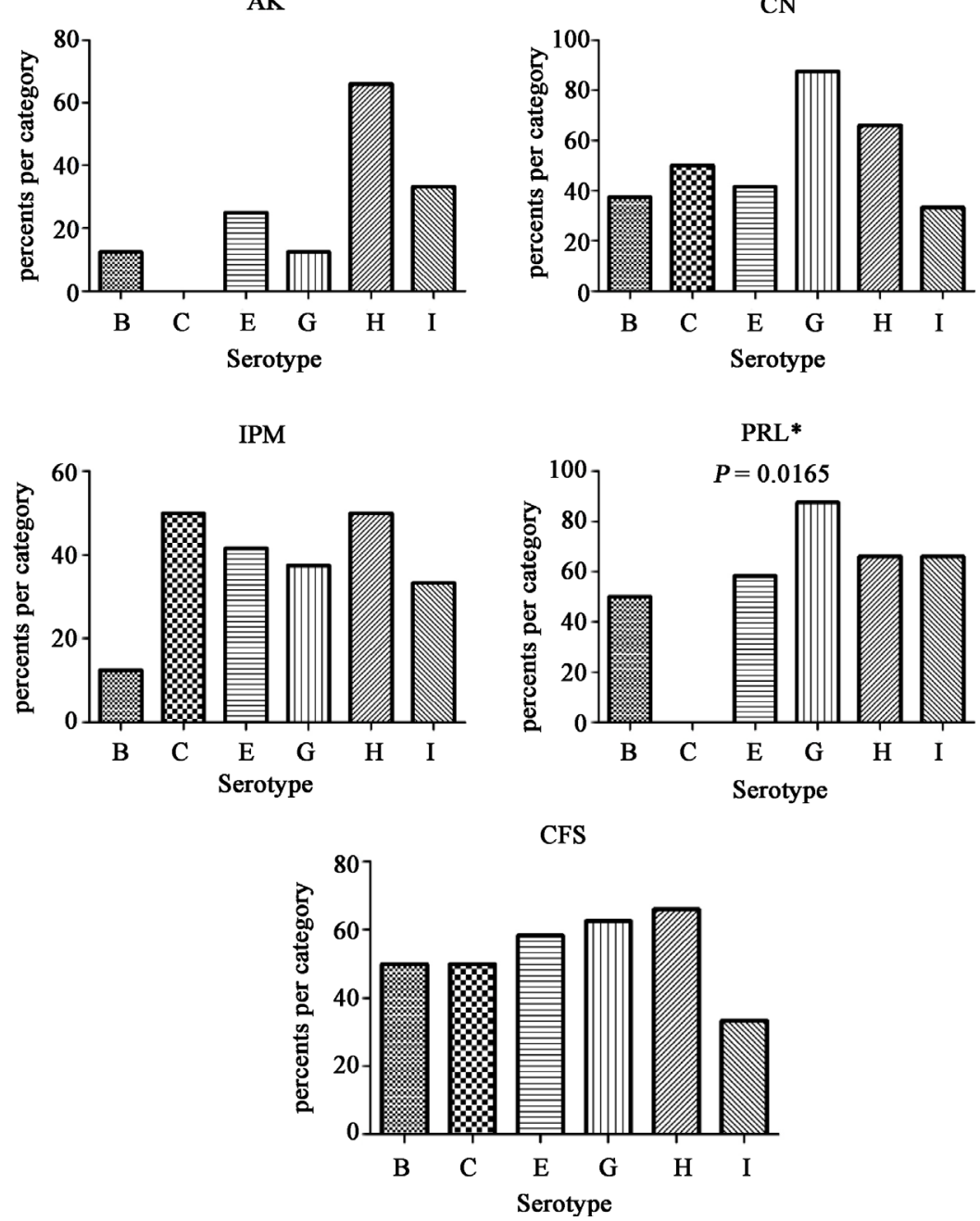

Figure 1. Frequency of different serotypes among antibiotic resistant isolates of $P$. aeruginosa. LEV: levofloxacin, CIP: ciprofloxacin, AK: amikacin, CN: gentamicin, IPM: imipenem, PRL: piperacillin and CFS: cefoperazone/sulbactam.

the most common profile shown by 11 isolates (28.2\%) followed by P3 and P7, each was present in 5 isolates $(12.8 \%)$. P4, P5 and P9 were presented by 4 (10.3\%), 2 (5.1\%) and $2(5.1 \%)$ isolates respectively. The least profiles detected were P2, P6, P8 and P10 (grouped into others); each was shown by only one isolate. A number of 6 isolates could not be typed (untypable). 


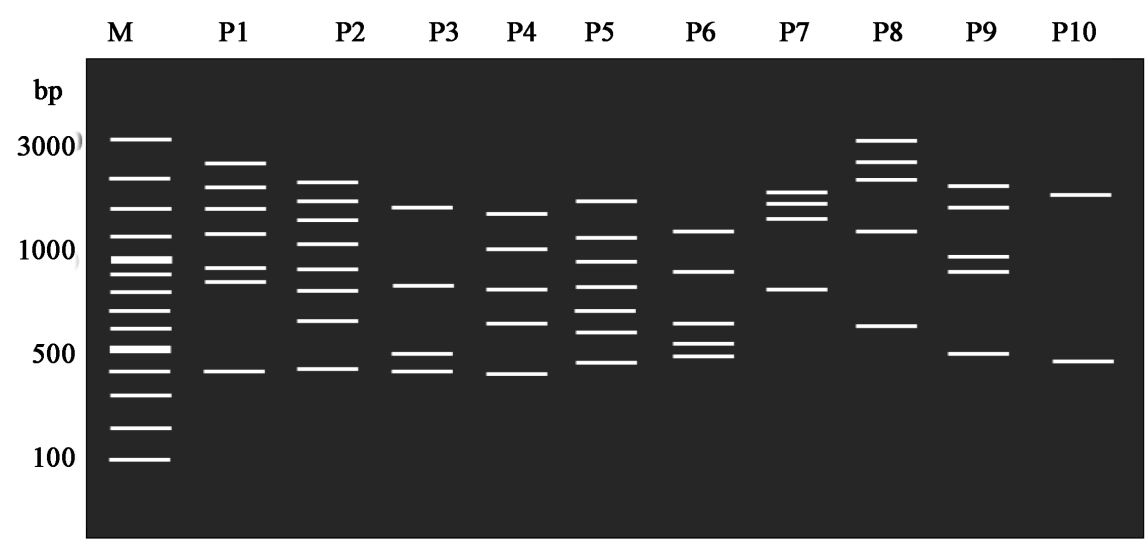

Figure 2. Schematic representation of genotypic profiles (P1-P10) of $P$. aeruginosa isolates from urine obtained byRAPD-PCR of M13 primer. bp: base pair, M: 100 bp plus DNA marker.

\subsection{Relationship between RAPD-M13 Genotypes and Antibiotic Resistance}

MDR isolates were highly associated with P1 profile (10/11; 90.9\%) and untypable isolates $(6 / 6 ; 100 \%)(P<0.0001)$. Studying the prevalence of RAPD-genotypic profile among resistant isolates revealed a significant association of $\mathrm{P} 1$ profile and untypable isolates with resistance to tested antibiotics $(P<0.05)$ (Table 3).

The results of serotyping, antibiotic susceptibility and RAPD-M13 genotyping of 39 isolates of $P$. aeruginosa were compared by binomial numerical methods using UPGMA software. The obtained dendrogram revealed a high degree of diversity between isolates (Figure 3). At 70\% similarity level, 21 clusters were found. The largest cluster comprised 12 isolates including all isolates of A1 antibiogram, 9/11 (81.8\%) of isolates of P1 RAPD profile. The prevalent serotypes (O6, O10, O11) accounted for 11/12 (91.6\%) of isolates in this cluster. Three subgroups comprising 2 to 3 isolates showed $100 \%$ similarity between isolates [isolates number $(1,5),(3,9,34)$ and $(13,23)$ ].

\section{Discussion}

$P$. aeruginosa is a major nosocomial pathogen that frequently causes urinary tract infections [25]. Studying its serotypes, antibiotic susceptibility and genotypic characterization will help in control of infection, and to improve outcome of treatment [26].

Of the 14 serogroups (20 serotyps) identified by IATS, only six serogroups ( 9 srotypes) were found (B, C, E, G, H and I). The present study revealed that serotypes $\mathrm{O} 11, \mathrm{O} 6$ and $\mathrm{O} 10$ were the dominant representing $66.6 \%$ of $P$. aeruginosa isolates. The frequency of incidence of different O-serotypes differs considerably among publications. Similar to our results, Lu et al., [27] found that O6 followed $\mathrm{O} 11$ and $\mathrm{O} 10$ were the commonest serotypes. Our results are in partial accordance with previous studies prevalence of other serotypes that reported O6 and 
Table 3. Distribution of Antibiotic resistance among different RAPD pattern.

\begin{tabular}{|c|c|c|c|c|c|c|}
\hline \multirow{2}{*}{ Antibiotics } & \multicolumn{6}{|c|}{$\begin{array}{c}\text { RAPD-Pattern } \\
\text { Number of isolates (\%) }\end{array}$} \\
\hline & $\begin{array}{c}\text { P1 } \\
\text { (11) }\end{array}$ & $\begin{array}{l}\text { P3 } \\
\text { (5) }\end{array}$ & $\begin{array}{l}\text { P4 } \\
(4)\end{array}$ & $\begin{array}{l}\text { P7 } \\
(5)\end{array}$ & $\begin{array}{l}\text { Others } \\
(8)\end{array}$ & $\begin{array}{c}\text { Untypable } \\
\text { (6) }\end{array}$ \\
\hline LEV & $\begin{array}{c}10 \\
(90.9 \%)\end{array}$ & 0 & $\begin{array}{c}2 \\
(50 \%)\end{array}$ & 0 & $\begin{array}{c}2 \\
(25 \%)\end{array}$ & $\begin{array}{c}5 \\
(83.3 \%)\end{array}$ \\
\hline CIP & $\begin{array}{c}10 \\
(90.9 \%)\end{array}$ & 0 & $\begin{array}{c}2 \\
(50 \%)\end{array}$ & 0 & $\begin{array}{c}2 \\
(25 \%)\end{array}$ & $\begin{array}{c}5 \\
(83.3 \%)\end{array}$ \\
\hline $\mathrm{AK}$ & $\begin{array}{c}6 \\
(54.5 \%)\end{array}$ & 0 & $\begin{array}{c}1 \\
(25 \%)\end{array}$ & 0 & 0 & $\begin{array}{c}3 \\
(50 \%)\end{array}$ \\
\hline $\mathrm{CN}$ & $\begin{array}{c}10 \\
(90.9 \%)\end{array}$ & 0 & $\begin{array}{c}2 \\
(50 \%)\end{array}$ & $\begin{array}{c}1 \\
20 \%\end{array}$ & $\begin{array}{c}2 \\
(25 \%)\end{array}$ & $\begin{array}{c}6 \\
(100 \%)\end{array}$ \\
\hline IMP & $\begin{array}{c}7 \\
(63.6 \%)\end{array}$ & $\begin{array}{c}1 \\
(20 \%)\end{array}$ & $\begin{array}{c}1 \\
(25 \%)\end{array}$ & $\begin{array}{c}2 \\
40 \%\end{array}$ & $\begin{array}{c}1 \\
(12.5 \%)\end{array}$ & $\begin{array}{c}2 \\
(33.3 \%)\end{array}$ \\
\hline PRL & $\begin{array}{c}10 \\
(90.9 \%)\end{array}$ & $\begin{array}{c}2 \\
(40 \%)\end{array}$ & $\begin{array}{c}2 \\
(50 \%)\end{array}$ & $\begin{array}{c}2 \\
40 \%\end{array}$ & $\begin{array}{c}3 \\
(37.5 \%)\end{array}$ & $\begin{array}{c}5 \\
(83.3 \%)\end{array}$ \\
\hline CFS & $\begin{array}{c}9 \\
(81.8 \%)\end{array}$ & $\begin{array}{c}2 \\
(40 \%)\end{array}$ & $\begin{array}{c}1 \\
(25 \%)\end{array}$ & $\begin{array}{c}2 \\
40 \%\end{array}$ & $\begin{array}{c}2 \\
(25 \%)\end{array}$ & $\begin{array}{c}6 \\
(100 \%)\end{array}$ \\
\hline MDR & $\begin{array}{c}10 \\
(90.9 \%)\end{array}$ & 0 & $\begin{array}{c}2 \\
50 \%\end{array}$ & $\begin{array}{c}1 \\
20 \%\end{array}$ & $\begin{array}{c}1 \\
(12.5 \%)\end{array}$ & $\begin{array}{c}6 \\
(100 \%)\end{array}$ \\
\hline
\end{tabular}

LEV: levofloxacin, CIP: ciprofloxacin, AK: amikacin, CN: gentamicin, IPM: imipenem, PRL: piperacillin and CFS: cefoperazone/sulbactam. MDR: multi-drug resistant.

O11 among the most common serotypes [26] [28] [29] [30]. In Egypt, El-Bialy et al. reported the prevalence of $\mathrm{O} 4$ and $\mathrm{O} 6$ serotypes in their study [25]. Hafez et al. [31] and Mohammed [32] reported O12 among the commonest serotypes detected. A study conducted by Elogne et al. [33] in Abidjan and Cattoen et al. [34] in Tunisia reported $\mathrm{O} 4$ as the most prevalent serotype. This may be attributed to the difference in specimen type and geographical location.

Nosocomial $P$. aeruginosa is associated with high resistance rates to antibiotics and frequent multidrug resistance [11]. This was demonstrated in the present study as more than $50 \%$ of isolates were MDR. A nearby percent of MDR $P$. aeruginosa (43.8\%) was reported by El-Domany et al. [35] and a higher percent (64\%) by Hashem et al. [36]. Our isolates were associated with high resistance rate to piperacillin, cefoperazone/sulbactam, gentamicin and quinolones (48.7\% - 61.5\%). Amikacin and imipenem were associated with lower resistance rates (25.6\% and 35\%, respectively). El-Bialy et al. reported similar results concerning the effectiveness of amikacin and imipenem [25]. These results disagreed with Abaza et al. who reported higher resistance to imipenem (78.3\%) [37]. Improper use of antibiotics explains the high resistance found among isolates. Levofloxacin, ciprofloxacin and piperacillin resistant isolates were significantly observed among the most prevalent serogroups, the same result was reported by Vizuje et al. [38].

Analysis of antibiogram revealed the association of MDR isolates with serotypes O6, O10 and O11. Previous studies reported prevalence of MDR P. aeruginosa among serotype O11 [33] [38] [39] [40]. In contrast to our results, Aydoğan et al. found association of susceptibility to all drugs and serotypes (O6, O11) and MDR was common among serotype O12 which was not detected in 


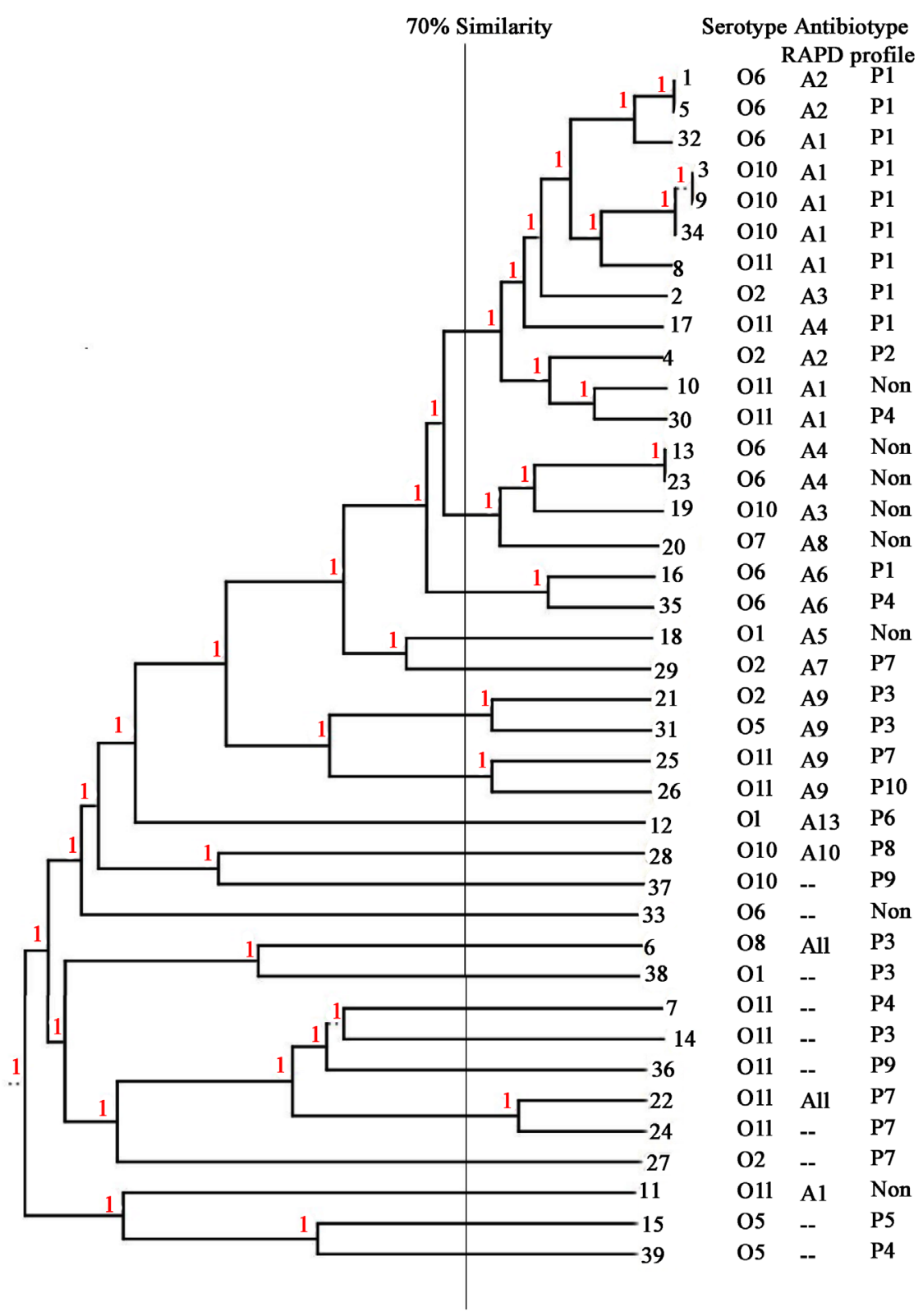

Figure 3. UPGMA dendrogram showing cluster analysis of $39 P$. aeruginosa isolates from urine based on serotyping, antibiotic susceptibility and RAPD-M13 genetic profiles. Non: non-typable.

the present study [41].

High polymorphisms (25.6\%) with 10 different profiles were obtained by RAPD-M13 fingerprinting. However, 6 isolates could not be genotyped, referred to as untypable, a similar result was reported by previous studies [42] [43]. The profiles were not unique as they were common for 2 to 11 strains. This was in agreement with Nanvazadeh et al. who revealed high polymorphism with 9 different genotypes [44]. Previous reports revealed different percentages of polymorphism. Aydoğan et al. and Nazaki et al. reported higher polymorphism, 96\% (90 genotype) and 43\% (21 genotype) [41] [44]. The variation in polymorphism 
among studies could be explained by difference in clinical source and level of quality control program applied in hospital where they isolated from. A statistically significant correlation was found between P1 (the most prevalent genotype) and MDR isolates. Except for existence of P1 among the prevalent serotypes, no obvious correlation was shown between serotypes and RAPD genotypes. Association between specific RAPD pattern and MDR isolates was established by a previous study [45]. However, Raafat et al. did not found such association in their study [43].

In dendrogram, combining the phenotypic and genotyping methods gave a high level of discrimination between isolates. The 39 isolates were classified into 21 clusters ( $>70 \%$ similarity). The largest cluster comprised most of $\mathrm{P} 1$ genotype isolates that were MDR but of different serotypes. This confirms that $P$. aeruginosa of the same genotype could be discriminated by phenotypic methods such as serotyping and susceptibility to antimicrobials [25] and vice versa [46]. Interestingly, two pairs of isolates (number 1, 5 and 13,23) and three isolates (number 3, 9 and 34) were placed in the same subgroup in this clusters showing $100 \%$ similarity. This strongly suggests the common source of infection in the hospital [43] [45]. In the present work, genotypic clusters show that the RAPD clonal lineage was not congruent with the serotypes of isolates. This leads to poor significant clusterization of isolates on using RAPD-M 13 alone [41].

For studying $P$. aeruginosa population, the use of phenotypic characteristics such as serotypes and antimicrobial susceptibility patterns together with genotypic characteristics confirms that more integrated information from a group of organisms reflects the biological reality of such population [47].

\section{Conclusion}

In the present study, serotypes $\mathrm{O} 11, \mathrm{O} 6$ and $\mathrm{O} 10$ were the most prevalent. Isolates showed high resistant rates to antipseudmonal antibiotics with high incidence of MDR isolates; that suggested the urgent need for revision of management and treatment policy to decrease the burden of resistant strains. Amikacin was the most effective antibiotic and piperacillin was the least effective one. A significant correlation was found between O6, O10 and MDR. A relatively high polymorphism was demonstrated among $P$. aeruginosa isolates by using RAPD-M13 fingerprinting. No clear correlation between serotypes and genotypes was found. On the other hand, antibiotic resistance was highly associated with genotype P1. Common source of infection is clear from isolates presenting uniform phenotypic and genotypic traits. The study illustrates the role of combining both phenotypic and genotypic characterization as a valuable way to study the epidemiology of $P$. aeruginosa infections for better assessment of treatment and infection control.

\section{Acknowledgements}

We thank Urology and Nephrology center, Mansoura, Egypt for providing the 
clinical isolates.

\section{Conflict of Interest}

The authors declare that there is no conflict of interest.

\section{References}

[1] GBuhl, M., Peter, S. and Willmann, M. (2015) Prevalence and Risk Factors Associated with Colonization and Infection of Extensively Drug-Resistant Pseudomonas aeruginosa: A Systematic Review. Expert Review of Anti-infective Therapy, 13, 1159-2270.

[2] Gellatly, S.L. and Hancock, R.E. (2013) Pseudomonas aeruginosa: New Insights into Pathogenesis and Host Defenses. Pathogens and Disease, 67, 159-173.

https://dor.org/10.1111/2049-632X.12033

[3] Juan, C., Peña, C. and Oliver, A. (2017) Host and Pathogen Biomarkers for Severe Pseudomonas aeruginosa Infections. The Journal of Infectious Diseases, 215, S44-S51. https://dor.org/10.1093/infdis/jiw299

[4] VVidal, F., Mensa, J., Almela, M., Martínez, J.A., Marco, F., Casals, C., et al. (1996) Epidemiology and Outcome of Pseudomonas aeruginosa Bacteremia, with Special Emphasis on the Influence of Antibiotic Treatment: Analysis of 189 Episodes. Arch Internal Med., 156, 2121-2126.

https://doi.org/10.1001/archinte.1996.00440170139015

[5] Ferreiro, J.L.L., Otero, J.Á., González, L.G., Lamazares, L.N., Blanco, A.A., Sanjurjo, J.R.B., et al. (2017) Pseudomonas aeruginosa Urinary Tract Infections in Hospitalized Patients: Mortality and Prognostic Factors. PLoS ONE, 12, e0178178. https://dor.org/10.1371/journal.pone.0178178

[6] Freitas, A.L.P. and Barth, A.L. (2002) Antibiotic Resistance and Molecular Typing of Pseudomonas aeruginosa: Focus on Imipenem. Brazilian Journal of Infectious Diseases, 6, 01-06.

[7] Czekajło-Kołodziej, U., Giedryskalemba, S. and Mędrala, D. (2006) Phenotypic and Genotypic Characteristics of Pseudomonas aeruginosa Strains Isolated from Hospitals in the North-West Region of Poland. Polish Journal of Microbiology, 55, 103-112.

[8] Faure, K., Shimabukuro, D., Ajayi, T., Allmond, L.R., Sawa, T. and Wiener-Kronish, J.P. (2003) O-Antigen Serotypes and Type III Secretory Toxins in Clinical Isolates of Pseudomonas aeruginosa. Journal of Clinical Microbiology, 41, 2158-2160. https://doi.org/10.1128/JCM.41.5.2158-2160.2003

[9] Legakis, N.J., Aliferopoulou, M., Papavassiliou, J. and Papapetropoulou, M. (1982) Serotypes of Pseudomonas aeruginosa in Clinical Specimens in Relation to Antibiotic Susceptibility. Journal of Clinical Microbiology, 16, 458-463.

[10] Gales, A.C., Jones, R.N., Turnidge, J., Rennie, R. and Ramphal, R. (2001) Characterization of Pseudomonas aeruginosa Isolates: Occurrence Rates, Antimicrobial Susceptibility Patterns, and Molecular Typing in the Global SENTRY Antimicrobial Surveillance Program, 1997-1999. Clinical Infectious Diseases, 32, S146-S155. https://dor.org/10.1086/320186

[11] Di Martino, P., Gagnière, H., Berry, H. and Bret, L. (2002) Antibiotic Resistance and Virulence Properties of Pseudomonas aeruginosa Strains from Mechanically Ventilated Patients with Pneumonia in Intensive Care Units: Comparison with Imipenem-Resistant Extra-Respiratory Tract Isolates from Uninfected Patients. Microbes 
and Infection, 4, 613-620. https://doi.org/10.1016/S1286-4579(02)01579-4

[12] Gad, G.F., El-Domany, R.A., Zaki, S. and Ashour, H.M. (2007) Characterization of Pseudomonas aeruginosa Isolated from Clinical and Environmental Samples in $\mathrm{Mi}$ nia, Egypt: Prevalence, Antibiogram and Resistance Mechanisms. Journal of Antimicrobial Chemotherapy, 60, 1010-1017. https://dor.org/10.1093/jac/dkm348

[13] Grundmann, H., Schneider, C., Hartung, D., Daschner, F.D. and Pitt, T.L. (1995) Discriminatory Power of Three DNA-Based Typing Techniques for Pseudomonas aeruginosa. Journal of Clinical Microbiology, 33, 528-534.

[14] Wolska, K., Kot, B. and Jakubczak, A. (2012) Phenotypic and Genotypic Diversity of Pseudomonas aeruginosa Strains Isolated from Hospitals in Siedlce (Poland). Brazilian Journal of Microbiology, 43, 274-282. https://dor.org/10.1590/S1517-838220120001000032

[15] Williams, J.G., Kubelik, A.R., Livak, K.J., Rafalski, J.A. and Tingey, S.V. (1990) DNA Polymorphisms Amplified by Arbitrary Primers Are Useful as Genetic Markers. Nucleic Acids Research., 18, 6531-6535. https://doi.org/10.1093/nar/18.22.6531

[16] Kumar, N.S. and Gurusubramanian, G. (2011) Random Amplified Polymorphic DNA (RAPD) Markers and Its Applications. Science Vision, 11, 116-124.

[17] Cruickshank, R., Duguid, J., Marmion, B. and Swain, R. (1975) Medical Microbiology. 12th Edition, Churchill Livingstone Edinburgh, London and New York.

[18] Macfaddin, J.F. (2000) Biochemical Tests for Identification of Medical Bacteria. 3rd Edition, Lippincott Williams and Wilkin Press, Philadelphia.

[19] Glupczynski, Y., Bogaerts, P., Deplano, A., Berhin, C., Huang, T.D., Van Eldere, J., et al. (2010) Detection and Characterization of Class A Extended-Spectrum-Beta Lactamase-Producing Pseudomonas aeruginosa Isolates in Belgian Hospitals. Journal of Antimicrobial Chemotherapy, 65, 866-871. https://doi.org/10.1093/jac/dkq048

[20] CLSI (2014) Performance Standards for Antimicrobial Susceptibility Testing. Twenty-Fourth Informational Supplement. CLSI Document M100-S24. Clinical and Laboratory Standards Institute, Wayne.

[21] Jean, S.S., Liao, C.H., Sheng, W.H., Lee, W.S. and Hsueh, P.R. (2017) Comparison of Commonly Used Antimicrobial Susceptibility Testing Methods for Evaluating Susceptibilities of Clinical Isolates of Enterobacteriaceae and Nonfermentative Gram-Negative Bacilli to Cefoperazone-Sulbactam. Journal of Microbiology, Immunology and Infection, 50, 454-463. https://doi.org/10.1016/j.jmii.2015.08.024

[22] Magiorakos, A.P., Srinivasan, A., Carey, R.B., Carmeli, Y., Falagas, M.E., Giske, C.G., et al. (2012) Multidrug-Resistant, Extensively Drug-Resistant and Pandrug-Resistant Bacteria: An International Expert Proposal for Interim Standard Definitions for Acquired Resistance. Clinical Microbiology and Infection, 18, 268-281. https://doi.org/10.1111/j.1469-0691.2011.03570.x

[23] Englen, M.D. and Kelley, L.C. (2000) A Rapid DNA Isolation Procedure for the Identification of Campylobacter jejuni by the Polymerase Chain Reaction. Letters in Applied Microbiology, 31, 421-426.

https://doi.org/10.1046/j.1365-2672.2000.00841.x

[24] Satpathy, G., Patnayak, D., Titiyal, J.S., Nayak, N., Tandon, R., Sharma, N., et al. (2010) Post-Operative Endophthalmitis: Antibiogram \& Genetic Relatedness between Pseudomonas aeruginosa Isolates from Patients \& Phacoemulsifiers. Indian Journal of Medical Research, 131, 571-577.

[25] El-Bialy, A.A., El-Shennawy, G.A., Mosaad, A.A. and Bendary, L.A. (2008) Phenotyping and Genotyping of Pseudomonas aeruginosa Urine Isolates in Zagazig Uni- 
versity Hospitals. The Egyptian Journal of Medical Microbiology, 17, 615-626.

[26] Estahbanati, H.K., Kashani, P.P. and Ghanaatpisheh, F. (2002) Frequency of Pseudomonas aeruginosa Serotypes in Burn Wound Infections and Their Resistance to Antibiotics. Burns, 28, 340-348. https://doi.org/10.1016/S0305-4179(02)00024-4

[27] Lu, Q., Eggimann, P., Luyt, C.E., Wolff, M., Tamm, M., François, B., et al. (2014) Pseudomonas aeruginosa Serotypes in Nosocomial Pneumonia: Prevalence and Clinical Outcomes. Critical Care, 18, R17. https://doi.org/10.1186/cc13697

[28] Fonseca, A.P., Correia, P., Sousa, J.C. and Tenreiro, R. (2007) Association Patterns of Pseudomonas aeruginosa Clinical Isolates as Revealed by Virulence Traits, Antibiotic Resistance, Serotype and Genotype. FEMS Immunology and Medical Microbiology, 51, 505-516. https://doi.org/10.1111/j.1574-695X.2007.00328.x

[29] Shehabi, A.A., Masoud, H. and BalkamMaslamani, F.A. (2005) Common Antimicrobial Resistance Patterns, Biotypes and Serotypes Found among Pseudomonas aeruginosa Isolates from Patient's Stools and Drinking Water Sources in Jordan. Journal of Chemotherapy, 17, 179-183. https://doi.org/10.1179/joc.2005.17.2.179

[30] Stanković-Nedeljković, N., Tiodorović, B., Kocić, B., Ćirić, V., Milojković, M. and Waisi, H. (2015) Pseudomonas aeruginosa Serotypes and Resistance to Antibiotics from Wound Swabs. Vojnosanitetski pregled, 72, 996-1003. https://doi.org/10.2298/VSP131224108S

[31] Hafez, S.F., Omar, N.Y., Abilelslam, H. and Salah, H. (1991) Multiple Typing of Pseudomonas aeruginosa Clinical Isolates from Different Hospital Departments. Bul Alex Fac Med, 27, 721-735.

[32] Mohammed, S. (2000) Susceptibility of Multiresistant Nosocomial Isolates of Pseudomonas aeruginosa to Trovafloxacin (A New Quinolone) and Their Typing by Sodium Dodecyl Sulphatepolyacryl-Amide Gel Electrophoresis (SDSPAGE). Faculty of Medicine, University of Alexandria, Alexandria.

[33] Elogne, C.K., Kalpy, J.C., Yeo, A., Guessennd, N., Anne, J.C., Ngoran, T.K., et al. (2018) Antibiotic Susceptibility and Serotype Patterns of Pseudomonas aeruginosa from Clinical Isolates in Abidjan, Cote dIvoire. African Journal of Microbiology Research, 12, 62-67. https://doi.org/10.5897/AJMR2017.8757

[34] Cattoen, C., Levent, T., Grandbastien, B., Descamps, D., Bouillet, L., Coignard, B., et al. (1999) Regional Survey of Pseudomonas aeruginosa in Northern France: Epidemiological and Microbiological Data. Médecine et Maladies Infectieuses, 29, 160-166. https://doi.org/10.1016/S0399-077X(99)80035-3

[35] El-Domany, R.A., Emara, M., El-Magd, M.A., Moustafa, W.H. and Abdeltwab, N.M. (2017) Emergence of Imipenem-Resistant Pseudomonas aeruginosa Clinical Isolates from Egypt Coharboring VIM and IMP Carbapenemases. Microbial Drug Resistance, 23, 682-686. https://doi.org/10.1089/mdr.2016.0234

[36] Hashem, H., Hanora, A., Abdalla, S., Shawky, A. and Saad, A. (2016) Carbapenem Susceptibility and Multidrug-Resistance in Pseudomonas aeruginosa Isolates in Egypt. Jundishapur Journal of Microbiology, 9, e30257. https://doi.org/10.5812/jjm.30257

[37] Abaza, A.F., El Shazly, S.A., Selim, H.S. and Aly, G.S. (2017) Metallo-Beta-Lactamase Producing Pseudomonas aeruginosa in a Healthcare Setting in Alexandria. Polish Journal of Microbiology, 66, 297-308. https://doi.org/10.5604/01.3001.0010.4855

[38] Vizujè, G., Pavilonis, A. and Kareivienè, V. (2007) The Peculiarities of Pseudomonas aeruginosa Resistance to Antibiotics and Prevalence of Serogroups. Medicina, 43, 36-42. 
[39] Al-Haddad, A.M. (2016) Serotypes and Antibiogram of Pseudomonas aeruginosa Isolated from Hospitals in Yemen. EC Microbiology, 4, 761-772.

[40] Loureiro, M.M., De Moraes, B.A., Mendonça, V.L.F., Quadra, M.R.R., Pinheiro, G.S. and Asensi, M.D. (2002) Pseudomonas aeruginosa: Study of Antibiotic Resistance and Molecular Typing in Hospital Infection Cases in a Neonatal Intensive Care Unit from Rio de Janeiro City, Brazil. Memórias do Instituto Oswaldo Cruz, 97, 387-394. https://doi.org/10.1590/S0074-02762002000300020

[41] Aydoğan, Ö.T., Çetin, I. and Köklükaya, Y. (2015) Clinical Isolates of Pseudomonas aeruginosa Cultured from Patients Admitted to the Intensive Care Unit (ICU). International Journal of Medicine and Medical Sciences, 5, 232-237.

[42] Menon, P.K., Eswaran, S.P., Pant, S.S., Bharadwaj, R. and Nagendra, A. (2003) Random Amplification of Polymorphic DNA Based Typing of Pseudomonas aeruginosa. Medical Journal Armed Forces India, 59, 25-28. https://doi.org/10.1016/S0377-1237(03)80099-0

[43] Raafat, M.M., Ali-Tammam, M. and Ali, A.E. (2016) Phenotypic and Genotypic Characterization of Pseudomonas aeruginosa Isolates from Egyptian Hospitals. African Journal of Microbiology Research, 10, 1645-1653. https://doi.org/10.5897/AJMR2016.8254

[44] Nanvazadeh, F., Khosravi, A.D., Zolfaghari, M.R. and Parhizgari, N. (2013) Genotyping of Pseudomonas aeruginosa Strains Isolated from Burn Patients by RAPD-PCR. Burns, 39, 1409-1413. https://doi.org/10.1016/j.burns.2013.03.008

[45] Hassan, R., Barwa, R., Shaaban, M.I. and Adel, L. (2015) Random Amplified DNA Polymorphism of Klebsiella pneumoniae Isolates from Mansoura University Hospitals, Egypt. African Journal of Microbiology Research, 9, 621-630. https://doi.org/10.5897/AJMR2014.7256

[46] Liu, Y., Davin-Regli, A., Bosi, C., Charrel, R.N. and Bollet, C. (1996) Epidemiological Investigation of Pseudomonas aeruginosa Nosocomial Bacteraemia Isolates by PCR-Based DNA Fingerprinting Analysis. Journal of Medical Microbiology, 45, 359-365. https://doi.org/10.1099/00222615-45-5-359

[47] Vandamme, P., Pot, B., Gillis, M., De Vos, P., Kersters, K. and Swings, J. (1996) Polyphasic Taxonomy, a Consensus Approach to Bacterial Systematics. Microbiological Reviews, 60, 407-438. 